\title{
A RARE CASE OF EOSINOPHILIC ESOPHAGITIS WITH ULCERATIVE PATTERN
}

\author{
Gelu C. ROSIANU ${ }^{1,2} \bowtie$, Cezar STROESCU ${ }^{3}$, Mihaela ROSIANU ${ }^{4}$, Narcis COPCA ${ }^{3}$ \\ ${ }^{1}$ CESITO CENTER, "Sfanta Maria" Clinical Hospital, Bucharest, Romania \\ ${ }^{2}$ Department of Gastroenterology, "Sfanta Maria" Clinical Hospital, Bucharest, Romania \\ ${ }^{3}$ Department of Surgery, "Sfanta Maria" Clinical Hospital, Bucharest, Romania \\ ${ }^{4}$ Department of Pediatric Cardiology, "M.S. Curie", Bucharest, Romania
}

Received 17 April 2021, Accepted 24 May 2021

https://doi.org/10.31688/ABMU.2021.56.2.15

\begin{abstract}
Introduction. Eosinophilic esophagitis (EoE) is a chronic, immune/antigen-mediated esophageal disease, considered to be caused by chronic, late-phase allergic reactions to various allergens, including food and environmental antigens.

Case presentation. A 27-year-old woman presented for dysphagia, chest pain, vomiting, weight loss and painful aphtoid lesions in the oral cavity. An upper digestive endoscopy has been performed, that revealed attenuation of the subepithelial vascular pattern, exudate and edema in the cervical esophagus. In the lower thoracic esophagus, numerous ulcerative lesions and extremely fragile mucosa with numerous white papules have been observed. Multiple biopsies have been obtained from the distal esophagus, that showed a high number of eosinophils (>15 eosinophils per high power field). After seven days of treatment with omeprazole, topical glucocorticoids (Fluticasone) and allergen elimination diet, an upper endoscopy was repeated, revealing a significant improvement in the macroscopic aspect of the esophageal mucosa. Eight weeks later, the endoscopic reevaluation showed normal esophageal
\end{abstract}

\section{RÉsumÉ}

Un cas rare d'osophagite éosinophilique de type ulcéreux

Introduction. L'œsophagite à éosinophiles (EoE) est une maladie œesophagienne chronique à médiation immunitaire/ antigénique. L'EoE est considérée comme causée par des réactions allergiques chroniques de phase tardive à divers allergènes, y compris les antigènes alimentaires et environnementaux.

Présentation du cas. Une femme de 27 ans est arrivée aux urgences pour se plaindre de dysphagie, de douleurs thoraciques, de vomissements, de perte de poids et de lésions aphteuses douloureuses dans la cavité buccale. Une endoscopie supérieure a été réalisée. Les caractéristiques endoscopiques ont été : atténuation du schéma vasculaire sous-épithélial, exsudat et œedème dans l'œsophage cervical. Dans l'œsophage thoracique inférieur, nous avons constaté de nombreuses lésions ulcéreuses, une muqueuse extrêmement fragile avec beaucoup de papules blanches. De multiples biopsies ont été obtenues à partir de l'œesophage distal qui ont montré une croissance du nombre d'éosinophiles (> 15 éosinophiles par champ). Après 
mucosa, biopsies containing less than 5 eosinophils per high power field.

Conclusions. EoE should be suspected in adults with a history of food impaction, with persistent dysphagia for solids, or with gastroesophageal reflux disease that fails to respond to medical therapy. In patients suspected of having EoE, the first diagnostic test is the upper endoscopy with esophageal biopsies. The early diagnosis of EoE in young patients with suspicious symptoms can help prevent further complications, such as fibrotic esophageal strictures or even Boerhaave's syndrome.

Keywords: eosinophilic esophagitis, esophageal stenosis, upper endoscopy, biopsies.

\section{INTRODUCTION}

Esophageal eosinophils were once considered to be an uncommon and rare finding. However, now they are considered a major cause of dysphagia in young adults. Eosinophilic esophagitis $(\mathrm{EoE})$ is a chronic, immune/antigen-mediated esophageal disease based upon the infiltration of the esophagus with large number of eosinophils, which lead to acute tissue lesions caused by the release of eosinophilic enzymes, followed by further fibrotic remodeling. Its pathophysiology is extremely complex, involving multiple factors, such as genetic predisposition combined with an altered immune response to common antigens, which determinates an aberrant $\mathrm{Th}_{2}$-reaction, leading to the activation of eosinophils, mast cells and basophils. Studies have shown a certain degree of correlation between EoE and other medical conditions, such as atopic dermatitis, asthma, metabolic syndrome, Mendelian diseases, like the "Iper-IgE syndrome", mast-cell activation syndromes, hypermobile connective tissue diseases, like Marfan, Ehler-Danlos and Loeys-Dietz syndromes. ${ }^{1}$

The diagnosis of EoE is based upon symptoms, endoscopic appearance, and histological findings. The diagnostic criteria are as follows: symptoms related to esophageal dysfunction, an esophageal eosinophil count of at least $15 \mathrm{eos} / \mathrm{high}$ power field, while sept jours de traitement par oméprazole, glucocorticoïdes topiques (fluticasone) et régime d'élimination des allergènes, une endoscopie supérieure a été répétée révélant une amélioration significative de l'aspect macroscopique de la muqueuse œesophagienne. À la semaine 8 , la réévaluation endoscopique a montré une muqueuse œesophagienne normale avec des biopsies contenant moins de 5 éosinophiles par champ.

Conclusions. Une œesophagite à éosinophiles doit être soupçonnée chez les adultes ayant des antécédents d'impaction alimentaire, une dysphagie persistante des solides ou un reflux gastro-œsophagien qui ne répond pas au traitement médical. Chez les patients soupçonnés d'avoir une œsophagite à éosinophiles, le premier test diagnostique est une endoscopie supérieure avec biopsies œsophagiennes. Le diagnostic précoce de l'œesophagite à éosinophiles chez les jeunes patients présentant des symptômes suspects peut aider à prévenir d'autres complications telles que des sténoses œsophagiennes fibreuses ou même le syndrome de Boerhaave.

Mots-clés: œsophagite à éosinophiles, sténose œsophagienne, endoscopie supérieure, biopsies.

excluding any other possible causes of eosinophilic infiltrate in the esophageal mucosa ${ }^{2}$.

The clinical manifestations of EoE vary with age. The most common symptoms in the pediatric population include loss of appetite, food rejection, staturoponderal delay, vomiting, abdominal pain and dysphagia. Common clinical manifestations seen in adults include dysphagia, food impactions and chest pain that is often located retrosternal and sometimes radiates posteriorly. The pain may not respond to antiacids. Last, but not least, spontaneous esophageal perforation (Boerhaave's syndrome) or esophageal perforation following endoscopy have also been reported ${ }^{3}$.

A variety of morphologic features in the esophagus have been described in patients with EoE. The following endoscopic features are common: attenuation of the subepithelial vascular pattern, stacked circular rings, strictures, linear furrows, white papules (representing eosinophil micro-abscesses) and small caliber esophagus ${ }^{4}$. There is an extremely rare morphologic subtype of EoS with ulcerative pattern, misleading the endoscopist regarding the real diagnosis. Studies have reported that only $1-3 \%$ of patients diagnosed with EoE have ulcerative pattern ${ }^{5}$.

Esophageal biopsies from patients with EoE show a high number of eosinophils, eosinophil micro-abscesses, and basal cell hyperplasia ${ }^{6}$. 
Barium studies can help to assess luminal narrowing, strictures and rings, and can be especially helpful in children?

The management of EoE includes "the six-food elimination diet" 8 and elemental diets to decrease allergen exposure ${ }^{9}$, topical glucocorticoids to decrease esophageal inflammation and endoscopic interventions, such as dilation.

Although topical glucocorticoids are an effective treatment option ${ }^{10}$, maintenance therapy with topical steroids is not recommended, because of side effects. It is indicated only in those with severe dysphagia or food impaction and high-grade esophageal stricture ${ }^{11}$. Among the most used topical steroids are Fluticasone and Budesonide ${ }^{12}$.

Dilation of esophageal strictures is effective for relieving dysphagia ${ }^{14}$. It is often reserved for patients who have failed more conservative therapies ${ }^{13}$ but may be required as initial therapy in patients with high-grade strictures. Mechanical (push-type or Bougie) dilators or balloon dilators are frequently used ${ }^{15}$.

\section{Case presentation}

A 27-year-old female presented to the Emergency Department for dysphagia, chest pain, vomiting, weight loss and painful aphtoid lesions in the oral cavity. The symptoms occurred in the last two

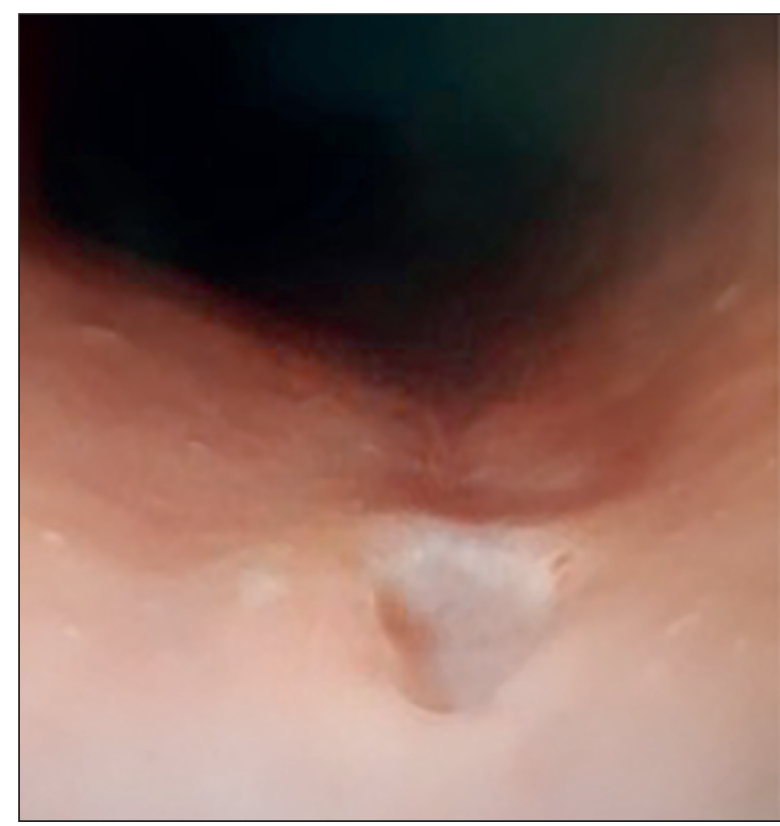

Figure 1. Upper digestive endoscopy - esophagus. Linear furrow and $5 \mathrm{~mm} / 7 \mathrm{~mm}$ ulcerative lesion, associated with pale, extremely fragile mucosa. The histopathological examination of the biopsy confirmed the diagnosis of eosinophilic esophagitis (over 30 eosinophils/high-power field plus numerous fibroblasts). months, with progressive accentuation. On clinical examination, she presented epigastric tenderness, without signs of peritoneal irritation. Laboratory tests showed moderate anemia. An upper digestive endoscopy has been performed, revealing attenuation of the subepithelial vascular pattern, exudate and edema in the cervical esophagus. In the lower thoracic esophagus, numerous ulcerative lesions, extremely fragile mucosa with multiple white papules (probably eosinophil-induced micro-abscesses) were observed. Multiple biopsies have been obtained from the distal esophagus (Fig. 1, 2).

The preliminary diagnosis based upon the symptoms and the macroscopic aspects revealed by the upper endoscopy imposed the necessity of making a differential diagnosis between gastroesophageal reflux disease, Crohn's disease, Behçet's disease and cytomegalovirus infection. Due to the medical history of the patient (asthma and atopic dermatitis), we inclined towards the diagnosis of EoE.

The histopathologic analysis confirmed the diagnosis of EoE. Number of over 30 eosinophils/high power field were identified, along with intercellular edema (spongiosis), and hyperplasia of the basal zone (Fig. 3,4).

Oral therapy with Omeprazole $80 \mathrm{mg} /$ day, along with Fluticasone $500 \mathrm{mg}$ twice a day and the six-food elimination diet were initiated. Even though the

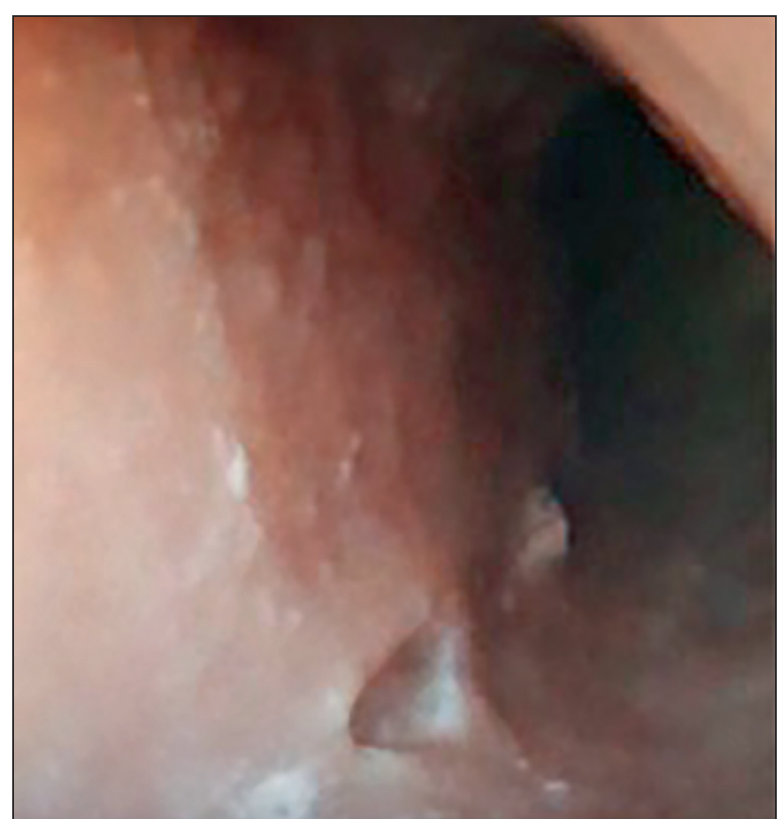

Figure 2. Upper digestive endoscopy - esophagus. Multiple white papules (eosinophil-induced micro abscesses) and ulcerative lesion, surrounded by fragile mucosa and attenuation of the subepithelial vascular pattern. 


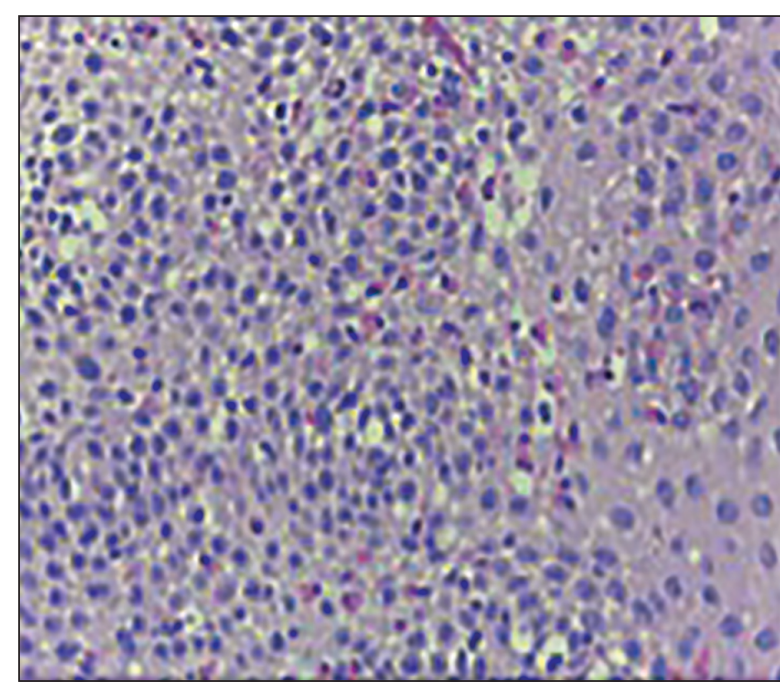

Figure 3. Microscopy. Hematoxylin Eosin, 40x. More than 15 intraepithelial eosinophils per high-power field have been encountered with in the esophageal mucosa, with eosinophil micro abscess formation (a cluster of at least four eosinophils), superficial layering of eosinophils.

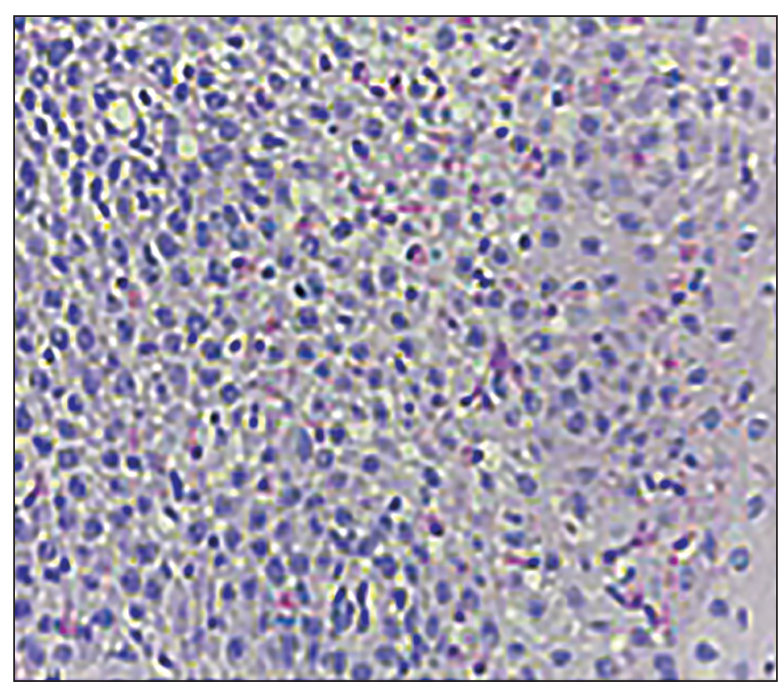

Figure 4. Microscopy. Eosinophil degranulation, and architectural changes including intercellular edema (spongiosis), hyperplasia of the basal zone, and elongation of the papillae. guidelines suggest that the first-line therapy should consist only in the oral administration of proton pump inhibitors (PPI) to test the patient's responsiveness to PPI, therefore classifying the severity of the EoE, we chose to initiate the simultaneous administration of PPI and fluticasone, because the mucosa had a high level of friability and the ulcers were very deep, with risk of perforation and mediastinitis. After seven days of therapy, obvious clinical improvement was seen. An upper endoscopy was repeated, with an improved macroscopic aspect of the mucosa. After eight weeks, the endoscopic evaluation showed a normal esophageal mucosa, biopsies identifying less than 5 eosinophils per high power field. The EoE was in the remission state. The patient was advised to follow the six-food elimination diet for the rest of her life, taking into consideration that she had the possibility to test certain groups of food over a period of eight weeks, followed by an endoscopic evaluation with biopsy sample in order to identify the food that could be included back into the diet, if they prove to not have an antigenic effect.

\section{Discussion}

This case is interesting because the ulcerative pattern is not specific for EoE. There are very few cases reported with this type of lesions ${ }^{16}$. Most cases have a fibro-stenotic pattern. Because ulcers and eosinophilic infiltrate can be found in other diseases, such as Crohn's disease ${ }^{17}$, milk protein-enteropathy (in children) and various types of vasculitis, the differential diagnosis was difficult. In addition, the diseases mentioned above are also responsive to fluticasone, making the differential diagnosis even more difficult. Due to the fact that there are no pathognomonic histologic criteria linked to EoE, the symptoms, clinical signs, endoscopic findings and response to pharmacological therapy may help to confirm the diagnosis. There are also a few infectious agents that can cause an ulcerative pattern of esophagitis, such as herpes simplex virus, cytomegalovirus, mycobacteria, syphilis and histoplasmosis ${ }^{18}$. They can be easily ruled out by the histopathological analysis and virological laboratory tests. The flow cytometry technique could be useful in identifying distinctive phenotypes of eosinophils in the patient's blood or cytokine patterns, guiding the gastroenterologist towards a more specific condition with elevated blood eosinophils, such as EoE, inflammatory bowel disease or simple allergic conditions. Eosinophils found in the blood of patients with EoE have a higher expression of the following cytokines: CD23, CD54, CRTH2 and CD11c, as international studies have previously reported ${ }^{19}$. Patients with EoE show increased mucosal impedance measured by esophageal impedance tests, correlated with increased epithelial permeability, leading to an easier intraluminal access of allergens ${ }^{20}$. Summarizing all these diagnostic methods, we suggest a complex study of patients suspected of EoE, to avoid a delayed accurate diagnosis and the occurrence of further complications.

\section{Conclusions}

EoE should be suspected in adults with a history of food impaction, with persistent dysphagia for 
solids, or with gastroesophageal reflux disease that fails to respond to medical therapy. In patients suspected of having EoE, the first diagnostic test is an upper endoscopy with esophageal biopsies. The management of EoE includes diets to decrease allergen exposure, topical glucocorticoids to decrease esophageal inflammation and endoscopic interventions.

\section{Author Contributions:}

G.C.R., C.S. and N.C. were responsible for the diagnostic procedures, clinical diagnosis, and treatment decisions. M.R. wrote the manuscript. All authors have read and agreed to the published version of the manuscript.

\section{Compliance with Ethics Requirements:}

"The authors declare no conflict of interest regarding this article"

"The authors declare that all the procedures and experiments of this study respect the ethical standards in the Helsinki Declaration of 1975, as revised in 2008(5), as well as the national law. Informed consent was obtained from the patient included in the study"

"No funding for this study"

\section{Acknowledgements:}

None

\section{References}

1. D'Allesandro A, Esposito D, Pesce M, Cuomo R, Domenico de Palma G, Sarnelli G. Eosinophilic esophagitis: From pathophysiology to treatment. World Journal of Gastrointestinal Pathophysiology 2015;6(4):150-158.

2. Dellon ES, Liacouras CA, Molina J, et al. Updated International Consensus Diagnostic Criteria for Eosinophilic Esophagitis: Proceedings of the AGREE Conference. Gastroenterology 2018; 155(4):1022-1033.

3. Lucendo A, Friginal-Ruiz A, Rodriguez B. Boerhaave's syndrome as the primary manifestation of adult eosinophilic esophagitis. Two case reports and a review of the literature. Diseases of the Esophagus 2011; 24(2):E11-15.

4. Enns R, Kazemi P, Chung W, Lee M. Eosinophilic esophagitis: Clinical features, endoscopic findings and response to treatment. Canadian Journal of Gastroenterology 2010; 24(9):547-551.
5. Raithel M, Hahn M, Donhuijsen K, et al. Eosinophilic gastroenteritis with refractory ulcer disease and gastrointestinal bleeding as a rare manifestation of seronegative gastrointestinal food allergy. Nutrition Journal 2017; 13:93.

6. Dellon E, Eosinophilic esophagitis: Diagnostic tests and criteria. Current Opinion in Gastroenterology 2012; 28(4):382-388.

7. Al-Haussaini A, AboZeid A, Hai A, How does esophagus look on barium esophagram in pediatric eosinophilic esophagitis? Abdominal Radiology 2016; 41(8):1466-1473.

8. Guajardo J, Plotnick L, Fende J, Collins M, Putnam P, Rothemberg M. Eosinophil-associated gastrointestinal disorders: a world wide web-based registry. Journal of Pediatrics 2002; 141(4):576-581.

9. Woon F, Chin Y, Ismail I, et al. Contribution of early nutrition on the development of malnutrition and allergic diseases in the first year of life: a study protocol for the mother and infant cohort study. BMC Pediatrics 2018; 18:233.

10. Greuter T, Straumann A. Medical algorithm: diagnosis and treatment of eosinophilic esophagitis in adults. Allergy 2020; 75(6):1522-1524.

11. Jeffrey A, Katzka D. Therapeutic options for eosinophilic esophagitis. Gastroenterology and Hepatology 2011; 7(1): 59-61.

12. Straumann A, Conus S, Degen L, et al. Budesonide is effective in adolescent and adult patients with active eosinophilic esophagitis. Gastroenterology 2010;139(5):1526-1537.

13. Schaefer E, Fitzgerald J, Molleston J, et al. Comparison of oral prednisone and topical fluticasone in the treatment of eosinophilic esophagitis: a randomized clinical trial in children. Clinical Gastroenterology and Hepatology 2008;6(2):165-173.

14. Dougherty M, Runge T, Eluri S, Dellon E. Esophageal dilation with either bougie or balloon technique as a treatment for eosinophilic esophagitis: a systematic review and meta-analysis. Gastrointestinal Endoscopy 2017;86(4):581-791.

15. Sami S, Haboubi H, Ang Y, et al. UK guidelines on esophageal dilatation in clinical practice. Gut 2018;67:1000-1023.

16. Priyadarshni S, Surapaneni B, Patel N. Upper gastrointestinal bleed in a young male - a rare presentation of eosinophilic gastroenteritis. Cureus 2020;12(2):e7059.

17. Mathur A, Ho L. Isolated Crohn's disease of esophagus: a rarest of rare presentation. Gastroenterology and Hepatology 2018; 9(5):168-170.

18. Yagain K, Rao L, Pai K, Pai G. Cytomegalovirus esophagitis in nonimmune-compromised patient - presenting as an acute necrotic esophagitis. Indian Journal of Pathology and Microbiology 2011;54:852-853

19. Johnsson M, Bove M, Bergquist $\mathrm{H}$, et al. Distinctive blood eosinophilic phenotypes and cytokine patterns in eosinophilic esophagitis, inflammatory bowel disease and airway allergy. Journal of Innate Immunity 2011;3(6):594-604.

20. Hirano I. Role of advanced diagnostics for eosinophilic esophagitis. Digestive Diseases 2014; 32(1-2):78-83. 